Article

\title{
How Spatial Distance and Message Strategy in Cause-Related Marketing Ads Influence Consumers' Ad Believability and Attitudes
}

\author{
Taemin Kim and Jeesun Kim *
}

check for updates

Citation: Kim, T.; Kim, J. How Spatial Distance and Message Strategy in Cause-Related Marketing Ads Influence Consumers' Ad Believability and Attitudes. Sustainability 2021, 13, 6775. https://doi.org/10.3390/su13126775

Academic Editor: Paweł Bryła

Received: 16 May 2021

Accepted: 10 June 2021

Published: 15 June 2021

Publisher's Note: MDPI stays neutral with regard to jurisdictional claims in published maps and institutional affiliations.

Copyright: (c) 2021 by the authors. Licensee MDPI, Basel, Switzerland. This article is an open access article distributed under the terms and conditions of the Creative Commons Attribution (CC BY) license (https:/ / creativecommons.org/licenses/by/ $4.0 /)$.
Department of Mass Communication, Incheon National University, Incheon 22012, Korea; taemin.kim@inu.ac.kr * Correspondence: jeesun@inu.ac.kr

\begin{abstract}
Corporations have engaged in cause-related marketing (CRM) based on consumer expectations toward ethical and sustainable corporate management. However, it is equally important to understand how to do so effectively. The role of cause proximity has been examined as an important factor that determines the effectiveness of CRM messages. Limited research, however, has considered moderating variables in the context of cause proximity. This study aimed to investigate the effect of the interplay between cause proximity and message strategy on attitudes toward the ad and ad believability. Based on an experimental design, this study applies construal level theory to demonstrate the effect of a construal fit between the spatial distance of the cause and how the message is presented on consumer attitudes toward ads and ad believability. Results show that the effects of message strategy mattered only for the global CRM cause. Furthermore, the findings show a mediating role of ad believability between cause proximity and message strategy on attitude toward the ad. This study provides empirical evidence for the advantage of using abstract messages in maximizing consumer reactions such as attitudes and believability when addressing global causes in CRM ad campaigns. Specifically, it offers insights on the impact of a matched condition between the spatial distance of the cause and language abstractness in CRM advertising.
\end{abstract}

Keywords: cause-related marketing (CRM) advertising; cause proximity; construal level theory; spatial distance; message strategy; advertising believability; attitudes toward ads

\section{Introduction}

Cause-related marketing (hereafter CRM) has received much attention in recent years, as marketers have shown increasing interest in achieving both sales and consumerrelationship goals by engaging in philanthropic activities [1]. CRM is defined as a marketing campaign or the process of marketing that incentivizes customers to purchase products or services through a company's contribution of a portion of the profit earned through purchases to a designated cause [2]. CRM advertising communicates this mutual benefit for the purpose of sales increase and brand promotion [3]. Previous studies have suggested that CRM advertising provides competitive advantages and helps to imbue brands with positive and favorable images [4]. From a sustainability perspective, corporations have adopted CRM based on consumer expectations regarding ethical and sustainable corporate management. There has been growing public interest in issues such as corporate social responsibility (CSR) and sustainability as problems like climate change have been a public focus of the media and science [5]. This research embraces the sustainable aspects of CRM advertising that can affect sustainable consumption by consumers as socially responsible consumption [6] at the attitudinal level.

An important factor in determining the persuasiveness of CRM advertising is cause proximity. Cause proximity determines whether a cause deals with local issues and beneficiaries (e.g., a person living in the country or state) or global issues and foreign beneficiaries 
(e.g., a person living overseas) [3]. Scholarly research has tested the effects of cause proximity on consumers' attitudes toward CRM ads and brands $[1,3,7,8]$. Advertising message strategy is also considered important in examining the effects of CRM advertising. The effectiveness of messaging strategy in advertising has been discussed in several studies $[9,10]$. Despite the tremendous attention to advertising methodology and advances in both research and practice in the field [11], there has been minimal research dedicated to the relationship between message strategy and cause proximity in CRM advertising.

Applying construal level theory (CLT) to the context of CRM advertising, this study aims to examine the interactive effect between cause proximity and message strategy on consumers' evaluation of CRM ads. This study suggests a theoretical link between the spatial distance of a cause and message abstractness in CRM ad evaluation. Furthermore, this study attempts to demonstrate an underlying mechanism whereby advertising believability plays a mediating role in the relationship between cause proximity and consumers' advertising evaluation in the context of CRM advertising.

\section{Literature Review and Theoretical Framework}

\subsection{Corporate Social Responsibility and Types of Cause-Related Marketing}

Corporate social responsibility (CSR) is defined as "a citizenship function with moral, ethical, and social obligations that provides the scaffolding for mutually beneficial exchanges between an organization and its public" [12] (p. 293). There have been growing expectations among consumers that companies and brands should engage in ethical business practices not only for their bottom line but to promote positive changes in our society. The more socially responsible the brand, the more supportive and loyal the consumers become. Research has shown a relationship between CSR and corporate marketing outcomes, suggesting that CSR has a direct positive effect on corporate brand credibility and corporate reputation [13].

Since CRM can serve as a strategic tool to showcase company involvement in CSR, it can enhance the effectiveness of CSR [14]. CRM comes in many forms. Seitanidi and Ryan [15] categorized these forms into several typologies based on corporations' motivations and expectations. A primary form of CSR campaign is a philanthropic or charitable donation. For example, when a company donates USD 1,000,000 to a charity, it is considered a charitable donation. The objective of the donation is to increase consumer brand recognition and corporate reputation by demonstrating goodwill to consumers [16]. CSR campaigns have evolved in recent years. Several new forms of CSR have emerged, such as sponsorship (e.g., USD 1,000,000 provided to the National Hockey Association) and patronage (e.g., USD 1,000,000 provided to independent filmmakers). Although traditional CSR campaigns can successfully achieve goals such as increased brand recognition or reputation, it is difficult to identify positive effects on sales. Thus, traditional CSR campaigns have been blamed for increasing costs without offering any tangible benefits to corporations, despite several studies that have indicated how CSR campaigns can create positive financial contributions for corporations [17-19].

To overcome this aforementioned weakness within traditional CSR, a new approach to CRM advertising has emerged. A clear example of CRM is a corporation providing a charity with a certain percentage of the money consumers spend for its product (e.g., $0.1 \%$ of the sales price will be given to a charity). CRM is a mixture of a traditional donation campaign and a marketing strategy to promote product sales and reinforce brand images. In other words, under CRM campaigns, companies can take positive action in the community if consumers purchase their products. Thus, a CRM campaign is a mutually beneficial campaign for both companies and consumers [15]. As for CRM strategies, Varadarajan and Menon [2] highlighted spatial distance not only in regard to the cause, but also in regard to the company's target audience. There are several types of CRM campaigns; however, from the perspective of beneficiaries, there are two types of CRM campaigns. As previously mentioned, the first is a CRM campaign focusing on a local cause, such as helping children in need within the country or the community. The second is a CRM 
campaign dealing with a global cause, such as helping African children in need. For this study, an advertisement promoting a local cause-related campaign is called a local CRM ad, while an ad promoting a global cause-related campaign is called a global CRM ad. We argue that construal level theory (CLT) can be applied to perceived cause proximity in the context of CRM advertising, with generating proximal or distant beliefs affecting the consumer response to advertising messages.

\subsection{Construal Level Theory in the Context of CRM Advertising}

Construal level theory (CLT) identifies the relationship between psychological distance and individuals' thought processes. CLT is based on the idea that individuals' thoughts and behaviors are influenced by the psychological distance that they perceive from a target event or object $[20,21]$. Psychological distance can be perceived by individuals' direct or indirect experiences and their existing knowledge (i.e., schema). It may or may not be different from actual distance. There are several dimensions of psychological distance: temporal distance, spatial distance, social distance, and power distance. Temporal distance defines how far an event or object is perceived in a temporal sense. For example, tomorrow is generally perceived as a closely occurring event, whereas "a month later" is perceived as a distant event. Social distance defines how far an event or object exists from an individual's social position or status. For example, a member of a city council is considered closer to most individuals than a senator. In the same way, spatial distance (which is the focus of this study) focuses on how far individuals perceive an event or object based on their current spatial position [22]. For example, individuals living in Minnesota may perceive that Paris is further than Roseville (a small city in Minnesota) even though they have not been to Paris.

According to CLT, psychologically distant events are construed in abstract terms and are more likely to be represented at a high construal level [23], whereas more proximal events are construed in a more detailed, contextual manner $[20,22,24]$. Thus, when individuals think about a psychologically distant event, this tends to evoke more abstract thoughts. This abstract thinking is called high-construal information. In other words, a psychologically distant event facilitates abstract thoughts (e.g., Paris: romance, love, art, etc., by someone outside France). In contrast, a psychologically near event prompts concrete information and low construal level thoughts (e.g., Seoul: convenient public transportation, clean streets, etc., by someone in Seoul). These concrete thoughts are called low-construal information. CLT suggests that there are different types of distances that can prime one's construal level, such as temporal distance and spatial distance.

According to Trope et al.'s [25] study, spatial distance influences individuals' response time to stimuli. They conducted an experiment using pictures showing an arrow pointing to either a spatially distant location or a close location. Inside the arrow, either a psychologically close entity (e.g., we, sure, tomorrow) or distant entity (e.g., others, maybe, year) was written. Researchers found that respondents' response times were faster when they viewed the stimulus that was congruent between the arrow and the denoted entity within the arrow. Specifically, if an arrow pointing to a distant location holds a distant entity inside the arrow (i.e., a congruent condition), response time was faster. In contrast, an incongruent stimulus delayed respondents' response time. A faster response time indicates that participants' responses are intuitive and natural. This natural flow can be interpreted as consistent with respondents' expectations and flow of information processing. Thus, the study suggested that distance-congruent stimulus has the potential to lead to favorable attitudes toward the stimulus. In other words, participants may feel comfortable and "correct" because they see expected information and do not need to use additional cognitive resources, which could lead to a positive evaluation [26].

Jia et al. [27] suggested that a spatially distant event is more likely to stimulate people's creative responses to the event compared to a spatially near event. In other words, when people are exposed to a spatially distant event, they tend to construe information at a high level using abstract terms and expressions. In contrast, when they are exposed to a spatially 
near event, they are more likely to construe information at a low level using concrete terms and expressions. Previous studies suggested that spatial distance influences people's response time to stimuli featuring different degrees of information concreteness [25]. The matched stimulus (i.e., a near event described through concrete information) leads to recipients' faster response time than the unmatched stimulus (i.e., a near event described through abstract information). Thus, when people view the matched stimulus, they may show more favorable attitudes because the information in the matched stimulus is more salient and accessible by recipients than the information in the unmatched stimulus.

Most important for the current study, psychological distance and construal levels have been linked to advertising effectiveness and performance [28]. In the context of advertising, Dhar and Kim [29] supported the positive influence of the matched stimulus. They used "receptivity" of a message, which is defined as "consumers' conscious and unconscious readiness to accept, process, and respond to" an ad message. According to their study, the spatial distance between an ad message and the location of the purchase decision is one important factor that moderates receptivity. They suggested that when evaluating a spatially near ad message, a peripheral feature and "feasibility" of the product (i.e., concrete information) is more persuasive to recipients. In contrast, a spatially distant ad is more persuasive when the message represents a core feature of the product and the "desirability" of the product (i.e., abstract information). In sum, an ad message representing spatial congruency between the message and consumers' purchase decisions will be more persuasive and effective than an incongruent ad message. This can be supported anecdotally by marketers' advertising messages. For example, outdoor ads or newspaper ads that exist at a far distance from the physical store location show relatively abstract information such as why the product is great and how positive the brand is in order to persuade consumers to go to a store or go online later. However, in-store ads that exist in close physical proximity to prospective consumers usually provide specific features and concrete details about the product, such as information about price cuts and coupon sales.

Drawing on construal level theory, recent CSR-CRM research [30] examined effects of spatial proximity of the firm (domestic company vs. foreign multinational corporation $(\mathrm{MNC})$ ), cause (domestic vs. global), and consumer cultural identity (locally oriented: nationalism and consumer ethnocentrism; globally oriented: global identity and global citizenship through global brands) on consumer attitudes toward the company. When companies engage in CRM with proximal causes, nationalistic consumers showed more favorable attitudes toward domestic firms compared to foreign MNCs. Their findings provide interesting insights on how consumers' local and global cultural identity beliefs can help explain the inconsistent findings of CRM strategies based on spatial distance effects in relation to the firm and the cause.

The present study applies this spatial distance to the CRM advertising context. As noted earlier, cause proximity and message strategy play important roles in persuasion using CRM ads. In CRM advertising, whether the cause is local or global (i.e., cause proximity) will prime consumers' perceived psychological distance. Additionally, the message strategy represented in CRM ads generates a more persuasive impact when the message strategy corresponds to the construal level primed by the cause proximity. In the context of print advertising for luxury brands, abstract advertising language was found to lead to a higher level of construal while concrete advertising language was found to lead to a lower level of construal [31]. From the perspective of construal level theory, their research provides implications that branding strategies based on product-centered vs. lifestyle can function as expressions of low- and high-level positioning strategies. In other words, abstract messages would generate more favorable attitudes and positive fluency in message processing toward global CRM ads because viewers' construal levels are relatively high in response to global causes that are physically and psychologically distant. On the other hand, concrete messages would generate more fluent message processing and favorable attitudes toward ads for local CRMs because viewers' construal levels are relatively low in 
response to local causes in close proximities. Based on this reasoning, the first and second hypotheses are proposed:

Hypothesis 1 (H1). A global CRM ad (a CRM ad focusing on a global cause) will generate a more favorable attitude toward the ad when abstract messages are used in the ad compared to when concrete messages are used.

Hypothesis 2 (H2). A local CRM ad (a CRM ad focusing on a local cause) will generate a more favorable attitude toward the ad when concrete messages are used in the ad compared to when abstract messages are used.

\subsection{The Mediating Role of Advertising Believability on Advertising Attitude}

Advertising believability is defined as "the extent to which an ad is capable of evoking sufficient confidence in its truthfulness to render it acceptable to consumers" [32]. Advertising believability has been applied in various advertising contexts: information about nutrition in advertising [33], political advertising [34], CSR image advertising [35], the effect on message receptivity in green advertising [36], etc. Overall, the results of these studies suggest that if consumers believe the advertising message, the advertising effectiveness and persuasiveness are more likely to be enhanced [37]. Nielsen [38] suggested that consumers' perceived believability and trust in an ad's advertising message generated more favorable attitudes toward the ad and more positive behaviors such as word-of-mouth recommendations. O'Cass and Griffin [39] examined the believability of advertising focusing on social issues. They found that involvement in and attention to the advertisement influenced social advertising believability, and this believability led to consumers' favorable attitudes toward the ad.

Several factors can influence advertising believability in CSR advertising. Previous studies have found that clear information about the related cause leads to more favorable consumer attitudes toward the ad [3]. Furthermore, Pomering and Dolnicar [35] demonstrated that advertising believability is influenced by consumers' prior knowledge surrounding the social issues discussed in CSR advertising. They explained these effects by using receptivity of the topics and messages. In other words, if consumers have ample prior knowledge about a particular social issue, they are more likely to receive the messages positively. In the meantime, literature in construal level theory has suggested that message receptivity is highly influenced by consumers' construal level [23]. Their study argues that consumers would feel "right" in a matched condition (i.e., a match between cause proximity and message strategy noted earlier in the H1 and H2). This matched condition and the idea of viewers "feeling right" was also suggested by Lee et al.'s [40] study. In the matched condition, viewers regard the message in the CRM ad as trustful and believable because they feel "right," and they, therefore, more easily accept the message through more fluent information processing [40].

More recently, Okuhara et al. [41] suggested that fluency in message processing led to positive evaluations of the ad. Processing fluency is associated with feeling right by the matched condition mentioned earlier, which means that the matched condition can enhance processing fluency and lead to consumers' positive attitudes toward the ad. Scholl et al. [42] supported this notion suggesting that fluency in message processing signals credibility in the message contents. In other words, the matched condition results in consistent mental representations and facilitates fluency of message processing, which can help to enhance the trustworthiness of the message compared to the unmatched condition. Thus, the following hypotheses are posited (see Figure 1).

Hypothesis 3 (H3). Advertising believability will be greater when abstract messages are used in a global CRM ad (a CRM ad focusing on a global cause) compared to when concrete messages are used. 
Hypothesis 4 (H4). Advertising believability will be greater when concrete messages are used in a local CRM ad (a CRM ad focusing on a local cause) compared to when abstract messages are used.

The enhanced credibility or believability of the message plays an important role in advertisements dealing with social issues like CSR or CRM ads. Based on Kim et al.'s [43] study, when viewers perceive a message as highly believable in green advertising, they find the message relevant and feel confident about their attitude toward the ad and the message. Ball, Manika and Stout [44] suggested that trust in the advertising message enhanced persuasiveness in the ad. Chan, Chan, and Tang [45] also suggested that higher advertising believability led to a more positive attitude toward the brand that is closely related to the attitude toward the ad. More specifically, Raziq et al. [46] examined the role of advertising believability in the consumer's attitude toward the ad. They suggested that if consumers perceived the advertising message as credible and trustworthy, they were more likely to show positive attitudes toward the ad. Taken together, if the matched condition between cause proximity and message strategy influences the believability of the advertising message positively, the enhanced advertising believability can lead to positive advertising attitudes (see Figure 1).

Hypothesis 5 (H5). Advertising believability will mediate the effect of cause proximity and message strategy on attitudes toward an ad.

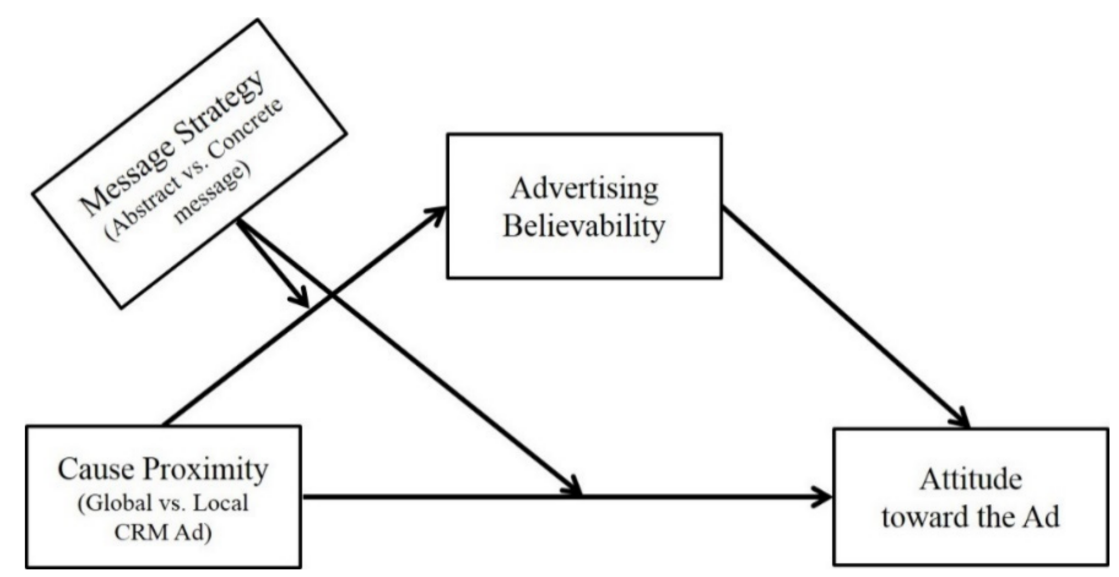

Figure 1. Theoretical model.

\section{Method}

\subsection{Experimental Design}

The hypotheses were tested on a 2 (cause proximity: global vs. local CRM ad) $\times$ 2 (CRM advertising message strategy: concrete message vs. abstract message) betweensubjects factorial design.

\subsection{Sample and Procedure}

Participants were recruited using Amazon Mechanical Turk (MTurk) between 2 June and 15 June 2020. In the recruiting process, we limited participants to US residents. They were granted USD 1 in exchange for participating in the study. A total of 100 participants completed the study. Nine participants were removed due to indicating great familiarity with the fictitious brand name used in the stimuli and not passing an attention check question. Therefore, a total of 91 samples were used for analysis. Forty-one participants were female $(45 \%)$, and 50 participants were male $(55 \%)$. The age of the respondents ranged from 18 to 71 years $\left(M_{\text {age }}=38.87 ; S D=11.38\right)$. Caucasians made up the major group $(n=73$; $80.22 \%)$ followed by African Americans $(n=9 ; 9.89 \%)$, Asian Americans $(n=6 ; 6.59 \%)$, Hispanic Americans $(n=2 ; 2.20 \%)$, and others $(n=1 ; 1.10 \%)$. 
The experiment was conducted online using a web-based research and survey questionnaire tool: Qualtrics. After signing a consent form, participants were randomly assigned to one of the four experimental conditions. Participants reviewed an ad with two pages (like a double-page ad in a magazine, for example). The first page of the ad showed a beneficiary of a cause and the place where the beneficiary lived. The second page described information about the cause and CRM. The purpose of the first page was to manipulate spatial distance and construal level through cause proximity. The message on the second page represented either a concrete or abstract message. Next, participants evaluated manipulation questions, dependent variables, and a set of demographic questions. Lastly, they were debriefed using an information page that briefly explained the purpose of the test before the test was completed.

\subsection{Stimuli and Manipulation of Independent Variables}

The stimuli were developed as two sets of double-page ads. The first page showed a child living in a relatively near proximity (Nebraska in the US) vs. a distant location (Bangladesh in Asia). This differing spatial distance (i.e., cause proximity) primed the participants' construal level. The second page contained information about the cause, the CRM campaign, and the brand. Two distinctive types of message strategy were employed: concrete messages and abstract messages. Message concreteness was manipulated using the linguistic category model (LCM) [47]. Based on the LCM, descriptive action verbs are perceived as more concrete, whereas adjectives are perceived as more abstract. Additionally, more examples and exact numbers associated with the cause were used in the concrete message conditions compared to the abstract message conditions. Thus, more descriptive action verbs (e.g., learn or attend) were used for the concrete message conditions, whereas adjectives (e.g., important or valuable) were used more for the abstract message conditions. As a result, four different sets of ads were created for the stimuli: (1) a locally targeted CRM ad with concrete messages, (2) a locally targeted CRM ad with abstract messages, (3) a globally targeted CRM ad with concrete messages, and (4) a globally targeted CRM ad with abstract messages. In order to create the stimuli, a fictitious coffee brand named "Moly Coffee" was created along with a corresponding brand logo. The topic of the cause was an early childhood education program supported by the brand through sales of the product. This information was consistent across all four conditions, with the exception of concreteness of the message in the ad.

\subsection{Measures}

Advertising Believability: Advertising believability was measured by three 7-point semantic differential scales adapted from Beltramini's [32] study. The items included: "unbelievable-believable," "dishonest-honest," and "not convincing-convincing."

Dependent measure: Consumer attitude toward the ad was used as a dependent measure. Attitude toward the ad was measured using four 7-point semantic differential scales [48]. The items included: "bad-good," "unfavorable-favorable," "unpleasantpleasant," and "negative-positive."

\section{Results}

\subsection{Manipulation Checks}

The manipulation check was conducted by measuring the perceived proximity in the ads using a 7-point item: "How close/far do you think the ad character lives from where you live?" adopted and adjusted from previous studies $[49,50]$. As expected, a $t$-test indicated that participants in a local cause condition perceived the ad character as closer than those in the global cause condition did $\left(M_{\text {Local }}=4.78\right.$ vs. $\left.M_{\text {Global }}=6.50, p<0.01\right)$. Thus, psychological distance (spatial distance) was successfully manipulated. The level of message concreteness was measured using six items. A sample item was completing the sentence: "The information or message in the ad is " by using two 7-point bipolar adjectives ("not specific/specific"). As expected, a $t$-test indicated that participants in the 
concrete message condition perceived the ad message as more concrete than those in the abstract message condition did $\left(M_{\text {Concrete }}=5.82\right.$ vs. $\left.M_{\text {Abstract }}=4.95, p<0.01\right)$.

\subsection{Interaction and Moderated Mediation Effects}

To test $\mathrm{H} 1$ through $\mathrm{H} 4$, a two-way MANCOVA was conducted to assess the influence of the two independent variables (i.e., cause proximity and message strategy) on attitude toward the ad and advertising believability, with age and educational attainment as covariates (see Tables 1 and 2). There was a statistically significant interaction effect between cause proximity and message strategy on the combined dependent variables $(F=3.956$, $p<0.05 ;$ Wilks' $\Lambda=0.91$ ).

Table 1. Means, SEs, and two-way MANCOVA results for attitude toward the ad.

\begin{tabular}{|c|c|c|c|c|}
\hline Source & MS & $d f$ & $F$ & Partial eta ${ }^{2}$ \\
\hline Cause Proximity & 3.14 & 1 & $4.36 *$ & 0.05 \\
\hline Message Strategy & 2.94 & 1 & 4.09 * & 0.05 \\
\hline \multirow[t]{3}{*}{ Cause Proximity $\times$ Message Strategy } & 4.76 & 1 & $6.61 *$ & 0.07 \\
\hline & \multicolumn{4}{|c|}{ Mean $(\mathrm{SE}, n)$} \\
\hline & \multicolumn{2}{|c|}{ Concrete Message } & \multicolumn{2}{|c|}{ Abstract Message } \\
\hline $\begin{array}{l}\text { Local CRM Ad } \\
\text { (Local Cause) }\end{array}$ & \multicolumn{2}{|c|}{$5.68(0.181, n=22)$} & \multicolumn{2}{|c|}{$5.58(0.185, n=22)$} \\
\hline $\begin{array}{l}\text { Global CRM Ad } \\
\text { (Global Cause) }\end{array}$ & \multicolumn{2}{|c|}{$5.60(0.180, n=23)$} & \multicolumn{2}{|c|}{$6.42(0.175, n=24)$} \\
\hline
\end{tabular}

Table 2. Means, SEs, and two-way MANCOVA results for advertising believability.

\begin{tabular}{|c|c|c|c|c|}
\hline Source & MS & $d f$ & $F$ & Partial eta $^{2}$ \\
\hline Cause Proximity & 0.92 & 1 & 0.84 & 0.01 \\
\hline Message Strategy & 0.42 & 1 & 0.38 & 0.00 \\
\hline \multirow[t]{3}{*}{ Cause Proximity $\times$ Message Strategy } & 6.33 & 1 & $5.75 *$ & 0.06 \\
\hline & \multicolumn{4}{|c|}{ Mean (SE, n) } \\
\hline & \multicolumn{2}{|c|}{ Concrete Message } & \multicolumn{2}{|c|}{ Abstract Message } \\
\hline $\begin{array}{l}\text { Local CRM Ad } \\
\text { (Local Cause) }\end{array}$ & \multicolumn{2}{|c|}{$5.49(0.224, n=22)$} & \multicolumn{2}{|c|}{$\begin{array}{l}\text { Local CRM Ad } \\
\text { (Local Cause) }\end{array}$} \\
\hline $\begin{array}{l}\text { Global CRM Ad } \\
\text { (Global Cause) }\end{array}$ & \multicolumn{2}{|c|}{$5.17(0.222, n=23)$} & \multicolumn{2}{|c|}{$\begin{array}{l}\text { Global CRM Ad } \\
\text { (Global Cause) }\end{array}$} \\
\hline
\end{tabular}

The adjusted means and standard errors of the attitude toward the ad in each condition are presented in Table 1 . The result showed a significant interaction effect between cause proximity and message strategy on the attitude toward the ad $(F(1,90)=6.61, p<0.05$, par. $\eta 2=0.07)$. More specifically, in the case of the distant cause, the attitude toward the ad was more favorable when abstract messaging was used $(M=6.42, S E=0.18)$ compared to concrete messaging $(M=5.60, S E=0.18, p<0.05)$. For the near cause, attitude toward the ad was more favorable when concrete messaging was used $(M=5.68, S E=0.18)$ compared to abstract messaging $(M=5.58, S E=0.185)$, but this mean difference was not significant (see Figure 2). Thus, H1 was supported, while H2 was not supported. 


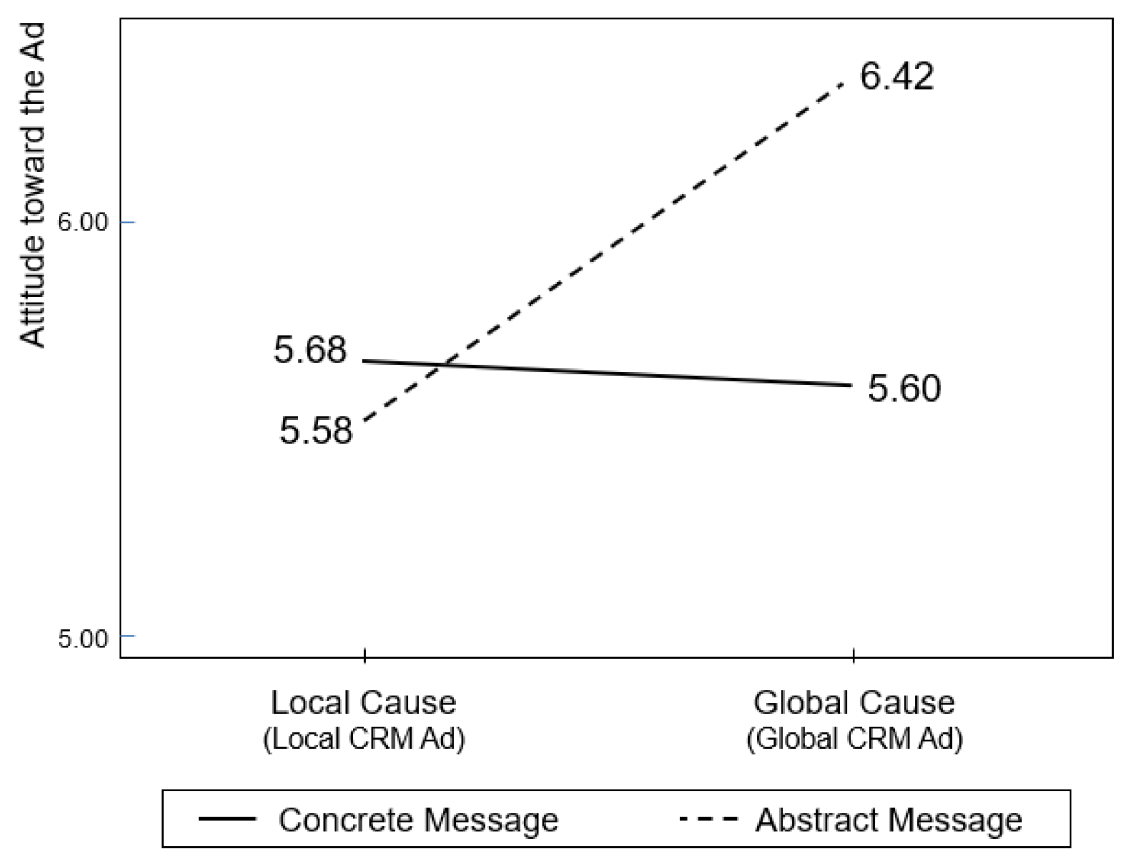

Figure 2. Interaction effect between cause proximity and message strategy on ad attitudes.

As for advertising believability, the adjusted means and standard errors in each condition are presented in Table 2. The interaction effect between cause proximity and message strategy on advertising believability was significant $(F(1,90)=5.75, p<0.05$, par. $\left.\eta^{2}=0.06\right)$. More specifically, in the case of the distant cause, advertising believability was higher when the abstract message was used $(M=5.84, S E=0.216)$ compared to the concrete message $(M=5.17, S E=0.222, p<0.05)$. For the near cause, advertising believability was higher when the concrete message was used $(M=5.49, S E=0.224)$ compared to the abstract message $(M=5.17, S E=0.222)$, but this mean difference was not significant (see Figure 3 ). Thus, H3 was supported, while H4 was not supported.

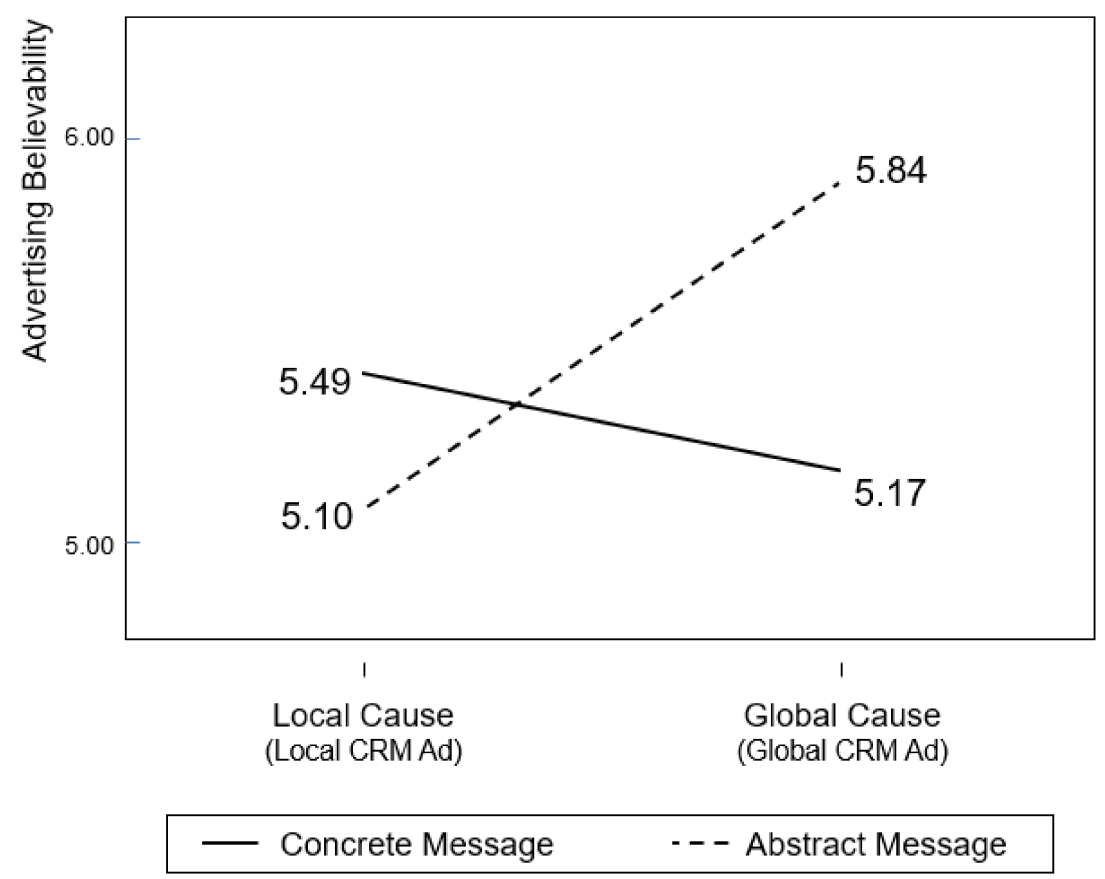

Figure 3. Interaction effect between cause proximity and message strategy on ad believability. 
H5 predicted that advertising believability would mediate the effect of cause proximity and message strategy on attitude toward the ad. Since H4 was not supported, the specific statement for $\mathrm{H} 5$ is that advertising believability would mediate the effect of cause proximity on attitude toward the ad when the cause is distant and abstract messaging is used. A moderated mediation analysis was run using the PROCESS macro for SPSS version 3.3. Cause proximity was entered as the main independent variable, message strategy was the moderating variable, and advertising believability was the mediating variable (Model 8 with 5000 bootstrap resamples) with the same covariates listed above (See Table 3). At the first step, results showed a significant interaction effect of cause proximity and message strategy on advertising believability $(B=1.062, S E=0.44, p<0.05)$. At the second step, advertising believability had a significant effect on attitude toward the ad $(B=0.443, S E=0.07, p<0.001)$ while the interaction effect of cause proximity and message strategy was not significant $(B=0.451, S E=0.31, n s)$. Bootstrapping indicated that advertising believability significantly mediated the relationship between cause proximity and advertising believability in the abstract message condition $(\Theta(x \rightarrow y) M=1=0.327,95 \%$ $\mathrm{CI}=[0.058,0.695]$, excluding zero). This mediation effect was not shown when concrete messaging was used $(\Theta(x \rightarrow y) M=0=-0.144,95 \% C I=[-0.515,0.163]$, including zero). Thus, this moderated mediation analysis showed the full mediating effect of advertising believability. In other words, advertising believability fully mediated attitudes toward the ad, which was observed when abstract messages were used for the global CRM ad. Thus, H5 was supported.

Table 3. Mediation analyses for message strategy x cause proximity.

\begin{tabular}{|c|c|c|c|c|}
\hline & \multicolumn{4}{|c|}{ Attitude toward the Ad } \\
\hline & \multicolumn{2}{|c|}{$B$} & \multicolumn{2}{|c|}{$t$} \\
\hline Advertising Believability & \multicolumn{2}{|c|}{0.44} & \multicolumn{2}{|c|}{$5.96^{* *}$} \\
\hline Message Strategy (A) & \multicolumn{2}{|c|}{0.08} & \multicolumn{2}{|c|}{0.36} \\
\hline Cause Proximity (B) & \multicolumn{2}{|c|}{0.06} & \multicolumn{2}{|c|}{0.30} \\
\hline $\mathrm{A} \times \mathrm{B}$ & \multicolumn{2}{|c|}{0.45} & \multicolumn{2}{|c|}{1.45} \\
\hline Covariates & \multirow{2}{*}{\multicolumn{2}{|c|}{0.00}} & \multirow{2}{*}{\multicolumn{2}{|c|}{0.39}} \\
\hline Age & & & & \\
\hline Education Attainment & \multicolumn{2}{|c|}{-0.14} & \multicolumn{2}{|c|}{-0.91} \\
\hline & \multicolumn{4}{|c|}{$R^{2}=0.623, F(1,90)=19.63$} \\
\hline \multirow{2}{*}{$\begin{array}{l}\text { Conditional Mediation by } \\
\text { Message Strategy }\end{array}$} & \multicolumn{4}{|c|}{ Bootstrapping Estimates } \\
\hline & Effect & SE & LLCI & ULCI \\
\hline Mediator: Advertising Believability & 0.327 & 0.162 & 0.053 & 0.695 \\
\hline
\end{tabular}

\section{Conclusions}

\subsection{Discussion}

The goal of this study was to investigate the effects of cause proximity and message strategy on consumers' attitudes toward CRM ads and ad believability. Cause proximity in CSR advertising functioned as an advertising cue that manipulated consumers' perceived psychological distance and primed their construal level. The findings showed that a global CRM ad caused consumers to be primed with a high construal level, which made abstract messages more salient and accessible as opposed to concrete messages. Thus, this effect led to more favorable attitudes toward the ad and ad believability. Furthermore, this study demonstrated that the ad believability mediated the effect of cause proximity and message strategy on the attitude toward the ad in the case of a global CRM ad containing abstract messages.

In the meantime, the effects of message strategies mattered only for the global CRM cause. In the local CRM cause, there was no difference between concrete and abstract messages in affecting attitudes toward the ad and ad believability. This was not consistent 
with the results of previous studies on CLT and message strategy. This may be because the cause in the local CRM ad implied a somewhat high construal level even though the distance was near. The cause in CRM advertising involves consumers' indirect participation in the initiative rather than asking for direct financial donations or active participation in the cause. CRM campaigns require customer participation through product purchase, but this is mediated by the company. Participants may feel that they participated in the cause, but they are generally not knowledgeable about what the company does on their behalf or whether their money is being used effectively for the cause. Thus, participants' psychological distance may not be considered near because of inconsistency between the actual spatial distance in the cause and the expected results of their participation (behaviors).

\subsection{Theoretical Contributions}

This study provides a meaningful implication for the literature on CRM advertising strategy. First, this study demonstrated a moderating role of message strategy of an ad in the effect of cause proximity. Previous studies have suggested that a near cause was more persuasive in general without considering other factors. For example, Grau and Folse [3] demonstrated the persuasiveness of concrete message strategy using signaling theory. However, their study did not show another moderating variable in the context of advertising messaging. Even though concrete messaging could be more effective in delivering the intended effects, it is not always ideal for consumers' evaluations.

Second, this study demonstrated the effect of cause proximity and message strategy on ad believability in the CRM advertising context. This result is aligned with $\mathrm{O}^{\prime} \mathrm{Cass}$ and Griffin's [39] study suggesting that advertising believability dealing with social issues influenced attitudes toward social issues (advertising message). Furthermore, they showed that advertising believability increased consumer intention to comply with the message regarding the targeted social issue. In other words, advertising believability can influence consumers' cognitive and behavioral responses toward CRM ads. Thus, this study extended the result of the previous research to the context of CRM advertising.

Third, this study demonstrated the mediating role of advertising believability in the effect of cause proximity and message strategy on consumers' attitudes toward the ad. A more suitable and matched CRM advertising message strategy based on cause proximity leads to an increase in consumers' advertising believability, and this increase, in turn, generates more positive attitudes toward the CRM ad. Thus, this study revealed an underlying mechanism behind the effect on the attitude toward the ad.

\subsection{Implications for Managers}

From a practical perspective, we suggest that before deciding which kind of message strategy to employ, advertisers should consider consumers' psychological distance and mental construal, which could make them sensitive to message-specific cues in the context of CRM advertising. The results indicate the advantage of using abstract messages in maximizing consumer reactions such as attitudes and believability when addressing global causes in CRM advertising campaigns. In addition to the effectiveness of abstract messages, our findings suggest the impact of a matched condition between the spatial distance of a cause and how the message is presented in CRM advertising. In particular, when consumers perceive the spatial proximity of a cause to be distant in engaging in a high-level construal, they are more likely to find a perceived connection with message abstractness emphasizing indirect implications for the cause (e.g., values for the cause), rather than with message concreteness suggesting direct implications for the cause (e.g., emphasis of suggested behavior). Therefore, the empirical evidence in this study suggests the importance of the matched condition between the spatial distance of the cause and message abstractness, which can offer strategic guidance in understanding consumer perceptions toward CRM advertising. Advertisers and marketers should adopt the match between the degree of 
message abstractness and the distance of the cause when crafting strategic messages for CRM advertising.

Second, this study provides practical implications for the implementation of effective CRM advertising. In contrast to other studies, this study employed the messages in the advertising stimuli to manipulate consumers' construal levels rather than using artificial methods used in other studies. For example, studies often asked participants in experiments to imagine they are doing something in a near or far future or to imagine they are in a close or faraway area [51,52]. However, this study used a more natural scenario and setting. Just as this study showed a set of two ads to participants, practitioners can create an ad composed of two serial ads or a double-page ad to increase the effectiveness of advertising. For example, advertisers can create a double-page magazine ad composed of a left-hand and a right-hand page. If their cause is designed to help children who live far away from us, the left-hand page of the ad can focus on cause proximity to prime consumers' construal level. Then, the right-hand page can show an abstract message to enhance consumers' attitudes toward the ad.

The findings also shed light on the potential effect of CRM ads on social and environmental benefits from the sustainability perspective. As consumers have become increasingly attentive to social and environmental issues, corporations are pressured to develop and exhibit ethical behaviors that can benefit society [53]. Marketers are encouraged to apply the psychological mechanism to make CRM ads more effective based on cause proximity, construal levels, and message abstractness that can ultimately influence consumers' sustainable consumption.

\subsection{Limitations and Future Research Directions}

Several limitations in the present study should be acknowledged. First, although our manipulation checks were successfully conducted for construal levels, other factors such as the topic of the cause could have activated perceived construal levels. The specific topic of the cause (the early childhood education program) was adopted in this study. Future studies should use other topics to extend the results of this study and further develop effective ways to manipulate consumers' construal levels, which can help ensure more external validity. A priori power analysis suggested a total sample size of 64 with power at the 0.5 level for the medium effect and a total sample size of 128 with power at the 0.8 level for the large effect [54]. The relatively small sample size of 91 participants could have limited statistical significance. Future research should replicate our study with a larger sample size.

Second, this study focused only on attitude toward the ad as a dependent variable. Previous research showed how CRM influences customers' willingness to pay and purchase intention $[55,56]$. Thus, future research can focus on other attitudinal and behavioral variables that would be influenced by enhanced ad believability. For example, researchers should investigate whether enhanced ad believability by the matched message strategy can influence consumers' attention to social issues in CRM ads or behavioral intention to donate or participate in the social issues.

An interesting avenue for future research would be to replicate the present study using irrelevant advertising cues. As Kulkarni and Yuan [57] demonstrated, irrelevant cues to advertising are more effective at priming viewers' construal levels. They showed a website displaying information about studying in a distant country (New Zealand) as an irrelevant cue to manipulate viewers' high or abstract construal level, whereas they showed similar but different information as an irrelevant cue, studying in the US. to manipulate their low construal level. The brand that they used for the advertisements was a fictitious deodorant product that was not relevant at all to information about where to study. Future studies can consider irrelevant cues to the cause and compare the effects with those using relevant message cues, such as in this study.

Another interesting topic for future research would be to extend spatial distance to another little-used dimension of psychological distance, such as perceived social distance 
from a character in the ad. Some CRM ads feature a famous person like a celebrity as a credible information source or an endorser of a prosocial cause, whereas some CRM ads use an ordinary person such as a beneficiary of the cause. In this case, a celebrity in the ad would be perceived as more socially distant than an ordinary person would be. Considering that many celebrities have participated in prosocial CRM advertising campaigns, it would be interesting to study the interaction effects between a celebrity character and the level of message concreteness.

Author Contributions: Conceptualization: T.K. and J.K.; methodology, T.K.; formal analysis, T.K.; interpretation of the results, T.K. and J.K.; writing-original draft preparation, T.K.; writing-review and editing, T.K. and J.K. Both authors have read and agreed to the published version of the manuscript.

Funding: This work was supported by the Incheon National University Research Grant in 2019.

Institutional Review Board Statement: This study was conducted with the approval of Incheon National University, in compliance with the guidelines and regulations of the university institutional review board for the method.

Informed Consent Statement: Informed consent was obtained from all subjects involved in the study.

Data Availability Statement: All relevant data are within the paper.

Conflicts of Interest: The authors declare no conflict of interest.

\section{References}

1. Ross, J.K., III; Stutts, M.A.; Patterson, L. Tactical considerations for the effective use of cause-related marketing. J. Appl. Bus. Res. JABR. 2011, 7, 58-65. [CrossRef]

2. Varadarajan, P.R.; Menon, A. Cause-Related Marketing: A Co-alignment of Marketing Strategy and Corporate Philanthropy. J. Mark. 1988, 52, 58-74. [CrossRef]

3. Grau, S.L.; Folse, J.A.G. Cause-related marketing CRM: The influence of donation proximity and message-framing cues on the less-involved consumer. J. Advert. 2007, 36, 19-33. [CrossRef]

4. Shabbir, S.; Kaufmann, H.R.; Ahmad, I.; Qureshi, I.M. Cause related marketing campaigns and consumer purchase intentions: The mediating role of brand awareness and corporate image. Afr. J. Bus. Manag. 2010, 4, 1229-1235.

5. Haunschild, R.; Leydesdorff, L.; Bornmann, L.; Hellsten, I.; Marx, W. Does the public discuss other topics on climate change than researchers? A comparison of networks based on author keywords and hashtags. J. Informetr. 2019, 13, 695-707. [CrossRef]

6. Webb, D.J.; Mohr, L.A.; Harris, K.E. A re-examination of socially responsible consumption and its measurement. J. Bus. Res. 2008, 61, 91-98. [CrossRef]

7. Dahl, D.W.; Lavack, A.M. Cause-Related Marketing: Impact of Size of Corporate Donation and Size of Cause-Related Promotion on Consumer Perceptions and Participation. Available online: https://www.researchgate.net/profile/Anne-Lavack/publication/30 9076419_Cause-related_marketing_impact_of_size_of_corporate_donation_and_size_of_cause-related_promotion_on_consumer_ perceptions_and_participation/links/58f53ac9458515ff23b56bee/Cause-related-marketing-impact-of-size-of-corporate-donationand-size-of-cause-related-promotion-on-consumer-perceptions-and-participation.pdf (accessed on 1 January 1995).

8. Sung, K.K.; Tao, C.W.W.; Slevitch, L. Restaurant chain's corporate social responsibility messages on social networking sites: The role of social distance. Int. J. Hosp. Manag. 2020, 85, 102429. [CrossRef]

9. Hyllegard, K.H.; Yan, R.N.; Ogle, J.P.; Attmann, J. The influence of gender, social cause, charitable support, and message appeal on Gen Y's responses to cause-related marketing. J. Mark. Manag. 2010, 27, 100-123. [CrossRef]

10. Singh, J.; Crisafulli, B. How intensity of cause-related marketing guilt appeals influences consumers: The roles of company motive and consumer identification with the brand. J. Advert. Res. 2020, 60, 148-162. [CrossRef]

11. Lee, S.J. The role of construal level in message effects research: A review and future directions. Commun. Theory. 2019, 29, 319-338. [CrossRef]

12. David, P.; Kline, S.; Dai, Y. Corporate social responsibility practices, corporate identity and purchase intention: Viability of a dual-process model. J. Public Relat. Res. 2005, 17, 291-313. [CrossRef]

13. Hur, W.M.; Kim, H.; Woo, J. How CSR leads to corporate brand equity: Mediating mechanisms of corporate brand credibility and reputation. J. Bus. Ethics 2014, 125, 75-86. [CrossRef]

14. Lerro, M.; Raimondo, M.; Stanco, M.; Nazzaro, C.; Marotta, G. Cause Related Marketing among Millennial Consumers: The Role of Trust and Loyalty in the Food Industry. Sustainability 2019, 11, 535. [CrossRef]

15. Seitanidi, M.M.; Ryan, A. A critical review of forms of corporate community involvement: From philanthropy to partnerships. Int. J. Nonprofit Volunt. Sect. Mark. 2007, 12, 247-266. [CrossRef] 
16. Arendt, S.; Brettel, M. Understanding the influence of corporate social responsibility on corporate identity, image, and firm performance. Manag. Decis. 2010, 48, 1469-1492. [CrossRef]

17. McGuire, J.B.; Sundgren, A.; Schneeweis, T. Corporate social responsibility and firm financial performance. Acad. Manag. J. 1988, 31, 854-872.

18. Herremans, I.M.; Akathaporn, P.; McInnes, M. An investigation of corporate social responsibility reputation and economic performance. Account. Organ. Soc. 1993, 18, 587-604. [CrossRef]

19. Du, S.; Bhattacharya, C.B.; Sen, S. Maximizing business returns to corporate social responsibility CSR: The role of CSR communication. Int. J. Manag. Rev. 2010, 12, 8-19. [CrossRef]

20. Trope, Y.; Liberman, N. Temporal construal. Psychol. Rev. 2003, 110, 403. [CrossRef]

21. Liberman, N.; Förster, J. The effect of psychological distance on perceptual level of construal. Cogn. Sci. 2009, 33, 1330-1341. [CrossRef]

22. Trope, Y.; Liberman, N. Construal-level theory of psychological distance. Psychol. Rev. 2010, 117, 440. [CrossRef]

23. Amit, E.; Algom, D.; Trope, Y. Distance-dependent processing of pictures and words. J. Exp. Psychol. Gen. 2009, 138, 400. [CrossRef]

24. Liberman, N.; Trope, Y. The psychology of transcending the here and now. Science 2008, 322, 1201-1205. [CrossRef]

25. Trope, Y.; Liberman, N.; Wakslak, C. Construal levels and psychological distance: Effects on representation, prediction, evaluation, and behavior. J. Consum. Psychol. Off. J. Soc. Consum. Psychol. 2007, 17, 83. [CrossRef]

26. Cesario, J.; Grant, H.; Higgins, E.T. Regulatory fit and persuasion: Transfer from "feeling right". J. Personal. Soc. Psychol. 2004, 86, 388. [CrossRef]

27. Jia, L.; Hirt, E.R.; Karpen, S.C. Lessons from a faraway land: The effect of spatial distance on creative cognition. J. Exp. Soc. Psychol. 2009, 45, 1127-1131. [CrossRef]

28. Theodorakis, I.G.; Painesis, G. The impact of psychological distance and construal level on consumers' responses to taboos in advertising. J. Advert. 2018, 47, 161-181. [CrossRef]

29. Dhar, R.; Kim, E.Y. Seeing the forest or the trees: Implications of construal level theory for consumer choice. J. Consum. Psychol. 2007, 17, 96-100. [CrossRef]

30. Strizhakova, Y.; Coulter, R.A. Spatial distance construal perspectives on cause-related marketing: The importance of nationalism in Russia. J. Int. Mark. 2019, 27, 38-55. [CrossRef]

31. Massara, F.; Scarpi, D.; Porcheddu, D. Can your advertisement go abstract without affecting willingness to pay? Product-centered versus lifestyle content in luxury brand print advertisements. J. Advert. Res. 2020, 60, 28-37. [CrossRef]

32. Beltramini, R.F. Advertising perceived believability scale. Proc. Southwest. Mark. Assoc. 1982, 1, 1-3.

33. Beltramini, R.F.; Evans, K.R.; Stan, S. Believability and comprehension of nutrition information in advertising. In American Marketing Association. Conference Proceedings; American Marketing Association: Chicago, IL, USA, 2000; Volume 11, p. 53.

34. O'Cass, A. Political advertising believability and information source value during elections. J. Advert. 2002, 31, 63-74. [CrossRef]

35. Pomering, A.; Dolnicar, S. Assessing the prerequisite of successful CSR implementation: Are consumers aware of CSR initiatives? J. Bus. Ethics 2009, 85, 285-301. [CrossRef]

36. Tucker, E.M.; Rifon, N.J.; Lee, E.M.; Reece, B.B. Consumer receptivity to green ads: A test of green claim types and the role of individual consumer characteristics for green ad response. J. Advert. 2012, 41, 9-23. [CrossRef]

37. Atkin, J.L.; Beltramini, R.F. Exploring the perceived believability of DTC advertising in the US. J. Mark. Commun. 2007, 13, 169-180. [CrossRef]

38. Nielsen, A. Global Trust in Advertising and Brand Messages, Nielsen Global Survey; ACNielsen: New York, NY, USA, 2012.

39. O'Cass, A.; Griffin, D. Antecedents and consequences of social issue advertising believability. J. Nonprofit Public Sect. Mark. 2006, 15, 87-104. [CrossRef]

40. Lee, A.Y.; Keller, P.A.; Sternthal, B. Value from regulatory construal fit: The persuasive impact of fit between consumer goals and message concreteness. J. Consum. Res. 2010, 36, 735-747. [CrossRef]

41. Okuhara, T.; Ishikawa, H.; Okada, M.; Kato, M.; Kiuchi, T. Designing persuasive health materials using processing fluency: A literature review. BMC Res. Notes 2017, 10, 198. [CrossRef]

42. Scholl, S.G.; Greifeneder, R.; Bless, H. When fluency signals truth: Prior successful reliance on fluency moderates the impact of fluency on truth judgments. J. Behav. Decis. Mak. 2014, 27, 268-280. [CrossRef]

43. Kim, Y.; Oh, S.; Yoon, S.; Shin, H.H. Closing the green gap: The impact of environmental commitment and advertising believability. Soc. Behav. Personal. Int. J. 2016, 44, 339-351. [CrossRef]

44. Ball, J.G.; Manika, D.; Stout, P. Causes and consequences of trust in direct-to-consumer prescription drug advertising. Int. J. Advert. 2016, 35, 216-247. [CrossRef]

45. Chan, F.Y.; Chan, H.F.; Tang, F. The effect of perceived advertising effort on brand perception: Implication for retailers in Hong Kong. Int. Rev. Retail. Distrib. Consum. Res. 2017, 27, 78-93. [CrossRef]

46. Raziq, M.M.; Ahmed, Q.M.; Ahmad, M.; Yusaf, S.; Sajjad, A.; Waheed, S. Advertising skepticism, need for cognition and consumers' attitudes. Mark. Intell. Plan. 2018, 36, 678-693. [CrossRef]

47. Semin, G.R.; Fiedler, K. The linguistic category model, its bases, applications and range. Eur. Rev. Soc. Psychol. 1991, 2, 1-30. [CrossRef] 
48. MacKenzie, S.B.; Lutz, R.J.; Belch, G.E. The role of attitude toward the ad as a mediator of advertising effectiveness: A test of competing explanations. J. Mark. Res. 1986, 23, 130-143. [CrossRef]

49. Chang, H.; Zhang, L.; Xie, G.X. Message framing in green advertising: The effect of construal level and consumer environmental concern. Int. J. Advert. 2015, 34, 158-176. [CrossRef]

50. Yan, D.; Sengupta, J.; Hong, J. Why does psychological distance influence construal level? The role of processing mode. J. Consum. Res. 2016, 43, 598-613. [CrossRef]

51. Martin, B.A.; Gnoth, J.; Strong, C. Temporal construal in advertising. J. Advert. 2009, 38, 5-20. [CrossRef]

52. Tangari, A.H.; Folse, J.A.G.; Burton, S.; Kees, J. The moderating influence of consumers' temporal orientation on the framing of societal needs and corporate responses in cause-related marketing campaigns. J. Advert. 2010, 39, 35-50. [CrossRef]

53. Goodstein, J.; Butterfield, K.D.; Pfarrer, M.D.; Wicks, A.C. Guest editors' introduction. Individual and organizational reintegration after ethical or legal transgressions: Challenges and opportunities. Bus. Ethics Q. 2014, 24, 315-342. [CrossRef]

54. Cohen, J. Statistical Power Analysis for the Behavioral Sciences, 2nd ed.; Lawrence Erlbaum: Mahwah, NJ, USA, 1988.

55. Koschate-Fischer, N.; Stefan, I.V.; Hoyer, W.D. Willingness to pay for cause-related marketing: The impact of donation amount and moderating effects. J. Mark. Res. 2012, 49, 910-927. [CrossRef]

56. Mendini, M.; Peter, P.C.; Gibbert, M. The dual-process model of similarity in cause-related marketing: How taxonomic versus thematic partnerships reduce skepticism and increase purchase willingness. J. Bus. Res. 2018, 91, 195-204. [CrossRef]

57. Kulkarni, A.A.; Yuan, H. Effect of Ad-Irrelevant Distance Cues on Persuasiveness of Message Framing. J. Advert. 2015, 44, 254-263. [CrossRef] 